\title{
Price Elasticity of Electricity Demand in Iran Based on Computable General Equilibrium Model
}

\author{
Nosratollah Abbaszadeh ${ }^{1}$, Ali Bahmani ${ }^{2}$ and Mina Qavami ${ }^{3}$ \\ ${ }^{1}$ Phd of Economics, Tehran University, Iran \\ ${ }^{2}$ University Teknologi, Malaysia \\ ${ }^{3}$ MA of Economics, Tehran University, Iran
}

\begin{abstract}
Based on the CGE model and according to Social Accounting Matrix (SAM) 1380, this study simulates the impact of electricity price adjustment on demand for electricity, and the simulation results show the range of electricity elasticity of different consumers. The elasticity of Residential sector is relatively larger. However, the absolute values of the price elasticity are less than one.

Furthermore, this paper quantitatively analyses the price elasticity of different categories of users, which are classified to Resident, Agriculture, Industry and Services. The elasticity absolute value of Residents is around (1.02$0.87)$, that of Agriculture is around (0.013-0.015), that of Industry is around $(0,013-0.032)$ and that of Services is around (0.02-0.031) in different scenarios.
\end{abstract}

The analytical results of this paper can provide corresponding support for the formulation of electricity pricing mechanisms for Iran.

Keywords: Electricity price; Price elasticity; CGE

\section{Introduction}

Electricity has always been regarded as one of the most essential commodities in the country, as manufacturing industries are not able to produce and households welfare would not be without it as well. In our country all forms of energy, including electricity has had a very low price over the years. Due to the low electricity prices, people did not economize in the use of electricity. Other consumer sectors such as industry used non-efficient technology due to low electricity prices compared to the prices of other factors of production and try to improve the efficiency by continuous usage of electricity power rather than other factors of production. There was no increase in electricity prices since 1384 and the prices had been remained stable in all sectors as previous year (1383) after approval of price-fixing scheme in seventh parliament and listed it in the fourth development plan. After the implementation of targeted subsidies plan from January 1389 to review the policy of subsidizing energy, Energy carriers such as electricity prices in the country rose to consumers in various sectors, especially of residential and industrial sectors and made them more sensitive to prices. This paper is an attempt to consider all economic agents behavior in a context of macroeconomic framework and assess impacts of electricity price increases in consumer demand in the various sectors and examine the use of this valuable resource that plays an important role in production process using a comprehensive model. Therefore, the aim of this paper is to examine the effects of electricity price increase on demand and estimate price elasticities using a Computable General Equilibrium Model (CGE). Since this model can balance all markets (supply and demand of goods and factors of production) and explain the relations between the sectors correctly, has more advantages than other models. Using this model, we can measure the impact of electricity price increase in different economic sectors, including residents, industry, agriculture and services accurately and estimate the price elasticity more accurately that could eventually help in the analysis and evaluation of policies and implementation of next steps in reforming the electricity price.

Questions can be posed in this context include:

- What is the price elasticity of electricity demand in different sectors?
- What is the result of comparing the price elasticity of demand in the residential, industrial and agriculture sectors?

- To answer these questions, the following two hypotheses are proposed:

- Electricity in all sectors is relatively inelastic good.

- The price elasticity of electricity demand in the residential sector is larger than the other sectors.

This paper is organized as follows: Section 2 provides an overview the literature. Section 3 deals with the methodology of the model. In this section Computable General Equilibrium Model and its database is provided. Section 4 contains the results of research, including calibration of the model and Price elasticity analysis and finally, the summery and conclusions of the study are presented.

\section{Literature Review}

General equilibrium models define a set of institutions and markets, that revenue and expenditure of each institution is equal and supply and demand in all markets is in equilibrium. It should be noted that the equations in CGE models are based on the assumption of optimizing behavior of consumers and producers in which households seek to maximize utility and producers maximize their profit. Walras equilibrium theory is the theoretical basis of these models.

The corner-stone of Walras's general equilibrium is this rule that all revenue from any activity should be equal to the amount of expenditures.

*Corresponding author: Nosratollah Abbaszadeh, Phd of Economics, Tehran University, Iran, Tel: +9821-66405047; Email: nabbaszd@ut.ac.ir

Received January 22, 2013; Accepted February 22, 2014; Published March 10 2014

Citation: Abbaszadeh N, Bahmani A, Qavami M (2014) Price Elasticity of Electricity Demand in Iran Based on Computable General Equilibrium Model. J Account Mark 3: 110. doi: 10.4172/2168-9601.1000110

Copyright: $(2014$ Abbaszadeh N, et al. This is an open-access article distributed under the terms of the Creative Commons Attribution License, which permits unrestricted use, distribution, and reproduction in any medium, provided the original author and source are credited. 
According to this rule, all firms' products are demanded by consumers and all stock of capital and labor supplied by households is demanded by firms. Also, for a particular commodity, the firms' product must be equal to the sum of the demands of consumers and other firms. The idea of multi-sector general equilibrium model was presented in Johansen`s study in 1960 [1]. The first multi-sector practical model with endogenous prices to estimate the resource allocation was offered by him. After that, extensive studies have been done on the impact of policies such as trade liberalization, fiscal policies and other price shock policies in the form of a system of equations.

Many studies have been done in the field of electricity demand globally. The study of Huathaker [2] by using the method of least squares is one of the first studies in this field. His study suggests that the elasticity of electricity demand in the UK is low. In Atakhanova's study [3] on the electricity market, electricity demand elasticities calculated in three residential, industrial and general in Kazakhstan. Household spending, economic restructuring, electricity prices and consumption in the previous period is considered as the most important variables in the household sector in which price elasticity of demand is very low.

Bianco [4] estimated the electricity demand function in Italy using data for the years 1970-2007. According to the results of this study, the amount of per capita income, electricity prices and the power consumption (with three lags) are involved in electricity demand function. Income elasticity is more than price elasticity and income elasticity of electricity demand is nearly $80 \%$. Also coefficients of structural changes, energy prices and other effective variables are negative and less than one.

Heyongxiu [5] in the study on the price elasticity of electricity demand calculated the effects of price changes on consumer demand in China based on the 2007 social accounting matrix in which the value obtained for the price elasticity is less than 1 in all sectors.

Among internal studies, research carried out by Pajouyan and Mohammadi [6] can be pointed out in which electricity demand assumed as a function of the real price of electricity and substitute energy prices and GDP. The results show that the price elasticity of electricity demand is less than one and the income elasticity is greater than one.

Khiabani [7] evaluated the effects of energy price increases in Iran based on CGE model in the form of three scenarios of gasoline prices increase, all energies price increase and all energies price increase in which the prices of petrol, diesel, fuel oil and electricity prices is equivalent to world prices. The results indicate that the increase of energy prices will reduce energy overuse in the firms and households and increase inflation.

Electricity price policy on the inflation has been investigated by Eslami [8] using a computable general equilibrium model and the results show that electricity prices will increase the general level of prices and inflation and if government cash subsidies are paid from revenues resulting from the global rise in oil prices and increased foreign aid is more efficient and leads to less increase in price index.

\section{Research Methodology}

As mentioned in the previous section, the model used in this paper is Computable General Equilibrium Model (CGE). In this model, production activities, which are producing goods in the economy, their revenue earned from the sale of goods and these revenues are used to pay the factors of production and intermediate goods. Goods prices in this model are a function of the prices of factors and intermediate goods that consumer prices are quite flexible and can change in a competitive atmosphere. So suppliers and demanders in this model are price takers that equate the quantity of supply and demand in a competitive environment.

Households who are the owners of factors earn income from stock of factors (i.e. labor and capital) and spend it to buy goods, pay taxes and savings. Demand function is derived from maximizing utility given the budget constraint.

In the factor market assume the following: (1) For Labor: free mobility across activities, unemployment with fixed, activity-specific real wages and the quantity of labor supply as the market-clearing variable; and (2) For Capital: full employment but no mobility between activities and a flexible market-clearing wage for each factor-activity combination.

Government revenue is obtained from income tax, sales tax, import, and export or activity tax. This revenue is spent on government consumption expenditures or transfer payments to other domestic organs. A part of government revenue may also be transferred abroad to repay foreign debts. The remaining revenue will be saved and positive or negative savings represent the deficit or surplus in the state budget.

Other countries engage in domestic financial markets by lending funds (as loan) or invest in financial markets and receive repayment of loans, attract funds or borrow money from local government. In addition, the interaction with other countries occurs through imports and exports. The assumption of this model is that the economy is small compared with the global economy. Thus, export and import prices are set at the global level. Transfer of workers' income that employed abroad into country and vice versa shows another dimension of relation between domestic and global economy.

\section{Mathematical statement of CGE model}

The CGE model is a set of equations describing the balance between supply and demand of the economic system. In this paper, the CGE model is divided into "blocks" for prices, production and commodities, institutions, and system constraints. All endogenous variables are written in uppercase Latin letters, whereas parameters (including variables with fixed or exogenous values) have lower-case Latin or Greek letters. In the model Latin letters a and c represent activities and commodities, respectively.

Price block: This block contains six equations that determine the relation of endogenous prices and other variables.

Import price: On the import and export side, the model incorporates the "small country" assumption that world prices are exogenous.

$$
P M_{c}=\left(1+t m_{c}\right) \cdot E X R \cdot p w m_{c}
$$

Where $\mathrm{PM}_{c}$ is the import price of commodity $\mathrm{c}$ in domestic currency, $\mathrm{tm}_{\mathrm{c}}$ is the rate of import tariff of commodity c, EXR is the foreign exchange rate (domestic currency per unit of foreign currency), pwm $_{\mathrm{c}}$ is the world import price.

\section{Export price:}

$$
P E_{c}=\left(1-t e_{c}\right) \cdot E X R \cdot p w e_{c}
$$

Where $\mathrm{PE}_{\mathrm{c}}$ is the export price of commodity c in domestic currency, $t_{c}$ is the export tax rate; pwe $_{c}$ is the world export price. 
Absorption equation: For each commodity, absorption-total domestic spending on the commodity at domestic demander pricesis expressed as the sum of spending on domestic output and imports, including an upward adjustment for the sales tax.

$$
P Q_{c} \cdot Q Q_{c}=\left[P D_{c} \cdot Q D_{c}+\left(P M_{c} \cdot Q M_{c}\right)\right]\left(1+t q_{c}\right)
$$

Where $\mathrm{PQ}_{\mathrm{c}}$ is the composite price of commodity $c, \mathrm{QQ}_{\mathrm{c}}$ is the quantity of commodity c supplied to domestic demanders (composite supply), $\mathrm{PD}_{\mathrm{c}}$ is the domestic price of commodity c, $\mathrm{QD}_{\mathrm{c}}$ is the quantity of domestic output $\mathrm{c}$ sold domestically, $\mathrm{QM}_{\mathrm{c}}$, is the quantity of import of commodity $\mathrm{c}, \mathrm{tq}_{\mathrm{c}}$ is the sales tax rate.

Domestic output value: For each commodity, domestic output value at producer prices is stated as the sum of the value of domestic output sold domestically and the export value.

$$
P X_{c} \cdot Q X_{c}=P D_{c} \cdot Q D_{c}+\left(P E_{c} \cdot Q E_{c}\right)
$$

Where $\mathrm{PX}_{c}$ is the producer price of commodity c, $\mathrm{QX}_{c}$ is the quantity of domestic output, $\mathrm{QE}_{\mathrm{c}}$, is the quantity of export of commodity $\mathrm{c}$.

\section{Activity price:}

$$
P A_{a}=\sum_{c \in C} P X_{c} \cdot \theta_{a c}
$$

Where PA is the price of activity a, $\theta_{\text {ac }}$ is the yield of commodity c per unit of activity a

\section{Value-added price:}

$$
P V A_{a}=P A_{a}\left(1-t x_{a}\right)-\sum_{c \in C} P Q_{c} \cdot i c a_{c a}
$$

Where PVA is the value-added price of activity a, tx is the tax rate for activity a, $\mathrm{ica}_{\mathrm{ca}}$ is the quantity of $\mathrm{c}$ as intermediate input per unit of activity a.

Production and commodity block: There are ten equations in this block that describe the supply side of the model.

Activity production function: Cobb-Douglas function is used for producer technology, where $\mathrm{QA}_{\mathrm{a}}$ is the level of activity $\mathrm{a}, \mathrm{ad}_{\mathrm{a}}$ is the production function efficiency parameter, $\mathrm{QF}_{\mathrm{fa}}$ is the quantity demanded of factor $f$ by activity $a, \alpha_{\mathrm{fa}}$ is the value-added share for factor $\mathrm{f}$ in activity a.

$$
Q A_{a}=a d_{a} \cdot \prod_{f \in F} Q F_{f a}^{\alpha_{f a}}
$$

Factor demand:

$$
W F_{f} \cdot W F D I S T_{f a}=\frac{\alpha_{f a} \cdot P V A_{a} \cdot Q A_{a}}{Q F_{f a}}
$$

Where $\mathrm{WF}_{\mathrm{f}}$ is the average wage (rental rate) of factor $\mathrm{f}, \mathrm{WFDIST}_{\mathrm{fa}}$ is the wage distortion factor for factor $\mathrm{f}$ in activity a.

Intermediate demand: The assumption of Leontief technology on intermediate inputs means that intermediate commodity demand (QINT) is defined as the product of the fixed (Leontief) input coefficients of demand for commodity c by activity a (ica ${ }_{c a}$ ) multiplied by the quantity of activity output (QA).

$$
Q I N T_{c a}=i c a_{c a} \cdot Q A_{a}
$$

Output function: This equation aggregates the commodity outputs by each activity.

$$
Q X_{c}=\sum_{a \in A} \theta_{a c} \cdot Q A_{a}
$$

Composite supply (Armington) function: Imperfect substitutability between imports and domestic output sold domestically is captured by a CES (constant elasticity of substitution) function in which the composite commodity that is supplied domestically is produced by domestic and imported commodities Economically, this means that demander preferences over imports and domestic output are expressed as a CES function

$$
Q Q_{c}=\alpha q_{c}\left[\delta_{c}^{q} Q M_{c}^{-\rho_{c}^{q}}+\left(1-\delta_{c}^{q}\right) Q D_{c}^{-} \rho_{c}^{q}\right]^{-1 / \rho_{c}^{q}}
$$

Where $\alpha \mathrm{q}_{\mathrm{c}}, \delta^{\mathrm{q}}$ and $\rho^{\mathrm{q}}{ }_{\mathrm{c}}$ are respectively the shift parameter, the share parameter and the exponent $\left(1 \rho_{c}^{q}\right)$ for Armington function.

Import-domestic demand ratio: This equation defines the optimal mix between imports and domestic output.

$$
\frac{Q M_{c}}{Q D_{c}}=\left[\frac{P D_{c}}{P M_{c}} \cdot \frac{\delta_{c}^{q}}{\left(1-\delta_{c}^{q}\right)}\right]^{1 /\left(1+\rho_{c}^{q}\right)}
$$

\section{Composite supply for non-imported commodities:}

$Q Q_{c}=Q D_{c}$

For commodities that are not imported, the Armington function is replaced by the above statement.

Output transformation (CET) function: Imperfect transformability between domestic output for exports and domestic sales is captured by a CET (constant elasticity of transformation) aggregation function. In economic terms, the difference between the Armington and CET functions is that the arguments in the former are inputs, those in the latter are outputs.

$$
Q X_{c}=\alpha t_{c}\left[\delta_{c}^{t} Q E_{c}^{\rho_{c}^{t}}+\left(1-\delta_{c}^{t}\right) Q D_{c}^{\rho_{c}^{t}}\right]^{1 / \rho_{c}^{t}}
$$

Where $\alpha t_{c} \delta_{c}^{t}$ and $\rho_{c}^{t}$ are respectively the shift parameter, the share parameter and the exponent $\left(1 \rho_{c}^{t}\right)$ for CET function.

Export-domestic supply ratio: This equation defines the optimal mix between exports and domestic sales as below:

$$
\frac{Q E_{c}}{Q D_{c}}=\left[\frac{P E_{c}}{P D_{c}} \cdot \frac{1-\delta_{c}^{t}}{\delta_{c}^{t}}\right]^{\left(1 / \rho_{c}^{t}-1\right)}
$$

Output transformation for non-exported commodities:

$$
Q X_{c}=Q D_{c}
$$

For commodities that are not exported, the CET function is replaced by a statement imposing equality between domestic output sold domestically and domestic output.

Institution block: This block contains six equations that define income and expenditure of institutions of the model; households (h), government (g) and rest of world (row).

\section{Factor income:}

$Y F_{h g, f}=\operatorname{shry} h g, f\left(\sum_{a \subset A} W F_{f} \cdot W F D I S T_{f a} \cdot Q F_{f a}+t r_{f, r o w} \cdot E X R\right)$

Where $\mathrm{YF}_{\mathrm{hgf}}$ is the transfer of income to institution hg from factor $\mathrm{f}$, shry $_{\mathrm{hg}, \mathrm{f}}$ is the share of the income from factor $\mathrm{f}$ in institution $\mathrm{hg}, \mathrm{tr}_{\mathrm{f} \text {, row }}$ is the income of factor $\mathrm{f}$ from rest of world and hg refers to domestic institutions (households and government).

Household income:

$Y H_{h}=\sum_{f \in F} Y F_{h f}+t r_{h, g o v}+E X R \cdot t_{h, \text { row }}$

Where $\mathrm{YH}_{\mathrm{h}}$ is the income to household $\mathrm{h}, \mathrm{YF}_{\mathrm{hf}}$ is the transfer of 
income to household $\mathrm{h}$ from factor $\mathrm{f}, \mathrm{tr}_{\mathrm{ii}}$ is the transfer from institution i' to institution i.

\section{Household consumption demand:}

$$
Q H_{c h}=\frac{\beta_{c h}\left(1-m p s_{h}\right) \cdot\left(1-t y_{h}\right) Y H_{h}}{P Q_{c}}
$$

Where $\mathrm{QH}_{\mathrm{ch}}$ is the quantity of consumption of commodity $\mathrm{c}$ by household $h, \beta_{\mathrm{ch}}$ is the share of commodity $\mathrm{c}$ in the consumption of household $\mathrm{h}, \mathrm{mps}_{\mathrm{h}}$ is the share of disposable household income to savings, ty $y_{h}$ is the rate of income tax.

\section{Investment demand:}

$$
Q I N V_{c}=\overline{q i n v_{c}} \cdot I A D J
$$

Where QINV is the quantity of investment demand, $\mathrm{q}$ invbarc is the base-year investment demand; IADJ is the investment adjustment factor.

\section{Government revenue:}

$$
\begin{aligned}
Y G= & \sum_{h} t y_{h} Y H_{h}+\sum_{c \in C} t q_{c}\left(P D_{c} \cdot Q D_{c}+\left(P M_{c} \cdot Q M_{c}\right)\right) \\
& +\sum_{c} t m_{c} \cdot E X R \cdot p w m_{c} \cdot Q M_{c}+\sum_{c} t e_{c} \cdot E X R \cdot p w e_{c} \cdot Q E_{c} \\
& +\sum_{a} t x_{a} \cdot P A_{a} \cdot Q A_{a}+\sum_{f} Y F_{g, f}+E X R \cdot t r_{g, r o w}
\end{aligned}
$$

Where $\mathrm{YG}$ is the government revenue, $\mathrm{YF}_{\mathrm{g}, \mathrm{f}}$ is the transfer of income to government from factor $\mathrm{f}$

\section{Government expenditures:}

$$
E G=\sum_{h} t r_{h, g}+\sum_{c} P Q_{c} \cdot q g_{c}
$$

Where EG is the government expenditure, $\mathrm{qg}_{\mathrm{c}}$ is the government commodity demand.

Market clearing conditions and system constraint block: This block defines the constraints that are satisfied by the economy as a whole without being considered by its individual agents. The model's micro constraints apply to individual markets.

\section{Factor markets:}

For the two factors, the closure rules are: unemployment with fixed, activity-specific real wages for labor and fixed capital use for each activity.

$$
\sum_{a} Q F_{f a}=Q F S_{f}
$$

Where $\mathrm{QFS}_{\mathrm{f}}$ is supply of factor $\mathrm{f}$.

$$
\begin{aligned}
& \text { Composite commodity markets: } \\
& Q Q_{c}=\sum_{a} Q I N T_{c a}+\sum_{h} Q H_{c h}+q g_{c}+Q I N V_{c}
\end{aligned}
$$

Current account balance: The current-account equation imposes equality between the country's earning and spending of foreign exchange. Foreign savings (FSAV) is equal to the current-account deficit

$$
\sum_{c} p w e_{c} \cdot Q E_{c}+\sum_{h g} t r_{\text {h. } r o w}+F S A V=\sum_{c} p w m_{c} \cdot Q M_{c}
$$

Savings-investment balance: This equation imposes equality between savings and investment, where the left hand side of equation refers to the total savings, the right hand refers to investment and WALRAS is a dummy variable that is zero at equilibrium.

$\sum_{a \in A} m p s_{h} \cdot\left(1-t y_{h}\right) \cdot Y H_{h}+(Y G-E G)+E X R \cdot F S A V=\sum_{a \in C} P Q_{c} \cdot Q I N V_{c}+W A L R A S$

Price normalization:

$\sum P Q_{c} \cdot c w t s_{c}=c p i$

Where cpi is the consumer price index and cwtsc is the commodity weight in CPI.

\section{Basic data base of CGE-SAM}

Data organizing for using the CGE model is of initial important steps to build the models. The required data for these models is provided in a matrix called Social Account Matrix (SAM) in which cash flow of goods and services and also payment between sectors is reflected. SAM matrix used in this study is macro-social accounting matrix of Iran 2001 (Table 1), which is the last matrix in this field. The matrix consists of seven accounts of goods and services, activities, factors, institutions, saving-investment, taxes and rest of world. To facilitate the calculation and tracking simulation results, in this paper the matrix is aggregated regarding following characteristics.

- Account of goods and services, which includes 22 commodity groups, is aggregated to two groups of electricity and other goods that are identified by subscript $\mathrm{c}$.

- Account of activities, including 21 activities, is aggregated to three activities of agriculture, industry and mining, services that are marked with subscript a.

\begin{tabular}{|c|c|c|c|c|c|c|c|c|c|c|}
\hline Commodities & & 417436 & & 397376 & 104733 & 206214 & & & & 157720 \\
\hline Activities & 1149118 & & & & & & & & & \\
\hline Factors & & 722717 & & & & & & & & 1003 \\
\hline Households & & & 439332 & & 46427 & & & & & 15 \\
\hline Government & & & 284388 & & & & 37040 & 8965 & 9386 & 1020 \\
\hline S-I & & & & 51358 & 189639 & & & & & \\
\hline Income Tax & & & & 37040 & & & & & & \\
\hline Sale Tax & & 8965 & & & & & & & & \\
\hline Import Tax & 9386 & & & & & & & & & \\
\hline Rest of World & 124975 & & & & & 34783 & & & & \\
\hline Total & 1283479 & 1628125 & 801304 & 485774 & 349846 & 240997 & 37040 & 8965 & 9386 & 159762 \\
\hline
\end{tabular}

- Account of factor in both original social accounting matrix and aggregated matrix consists of two factors, labor and capital which will be shown with subscript $f$.

- Account of households is introduced in two forms of rural and urban households and since the merging of enterprises and government does not create disturbance in our discussion, these two institutions have been merged. So the institutions of model are urban households, rural households, government and rest of world. This part is shown with subscript $i$.

Table 1: Macro-SAM of 2001 (unit: Billion Rials). 


\begin{tabular}{|c|c|c|c|c|}
\hline Sectors & $\mathbf{5 \%}$ & $\mathbf{1 0 \%}$ & $\mathbf{1 5 \%}$ & $\mathbf{2 0 \%}$ \\
\hline Residents & -1.029 & -0.958 & -0.91 & -0.871 \\
\hline Agriculture & -0.015 & -0.014 & -0.013 & -0.013 \\
\hline Industry & -0.033 & -0.021 & -0.016 & -0.013 \\
\hline Services & -0.031 & -0.024 & -0.022 & -0.02 \\
\hline
\end{tabular}

Table 2: Values of price elasticity of electricity demand.
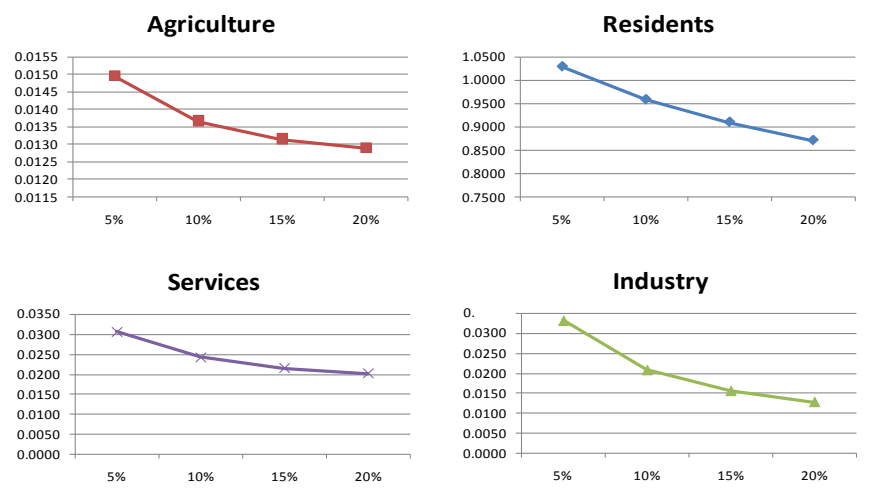

Figure 1: The trend of price elasticity of electricity demand

- Saving-Investment account represents institutions savings and on the other hand, investment demand for different goods.

- Taxes as well as production factors remained unchanged and consist of three types of taxes (income tax, sales tax, and taxes on imports).

\section{Simulation Results}

\section{Model calibration}

One of the important steps in modeling general equilibrium models is to calibrate the model. Calibration is a process of determining the parameter values so that the values of the endogenous variables for the base year to be reproduced. In fact, the aim of calibration is that general equilibrium that is presented in the form of mathematical equations should be reproduced the values of the SAM in the first run. In other words, when the general equilibrium model is solved, the same amount of social accounting matrix is obtained as the answer of the model.

CGE model has two types of parameters: the first type such as share of households and government consumption of different goods, savings rates, tax rates and etc., is called share parameters. These parameters which derived from the SAM are obtained using the GAMS software. The second type is behavioral parameters, including Armington function's elasticity and CET function's elasticity. To obtain these parameters previous studies and past research in the country or similar countries are used. In this paper import substitution elasticity (Armington function elasticity of substitution) and export elasticity of substitution (CET function elasticity of substitution) respectively 0.5 and 2 is assumed by Heyongxiu ${ }^{1}$.

\section{Analysis of price elasticity of electricity demand}

Generally, electricity demand is in form of final demand from households and in form of intermediate demand from the firms. This section introduces the scenarios (Four Scenarios: 5\%, 10\%, 15\% and $20 \%$ increase in electricity prices) and the effects of energy price

${ }^{1}$ For this purpose we use Heyongxiu [5] and Naderan and Fouladi (2006). increases on demand based on the equation $E=\frac{\Delta Q / Q}{\Delta P / P}$ in all sectors
is investigated.

By calibrating the model and obtained parameters and also applying above mentioned scenarios using GAMS software for the price elasticity of electricity demand the results obtained are presented in Table 2. According to this table, the price elasticity of electricity demand in all sectors is negative. It indicates the establishment of demand law for electricity. The absolute value of the elasticity in all sectors and all scenarios (except residential sector in the first scenario) is less than one and we can say electricity relatively inelastic good in all sectors. Thus, the first hypothesis of this paper is accepted. In addition, price elasticity of households demand for electricity in all scenarios is larger than the other sectors. This may be due to low price of electricity and using luxury accessories at homes that with rising prices the incentive to save and reduce the use of these materials occurs. So, the second hypothesis based on the higher price elasticity of electricity demand in the household sector relative to other sectors is accepted.

The high volatility of electricity prices results lower price elasticity in all consumption sectors. This indicates that in the early stages of rising prices greater capacity is in available for saving power consumption for people and with subsequent price increases the capacity will be decreased. This is illustrated in Figure 1.

As reference [7] Khiabani mentioned the price elasticity of electricity demand in most countries is less than one. It should be noted that the price elasticity of electricity demand in the residential sector in developed countries is usually larger, that is due to high level of welfare and use of facilities and luxury equipment. In this study the price elasticity in the residential sector is around one. From this point of view we can say that the results for the household sector are similar to studies conducted on developed countries. The results show the low electricity elasticity in other sectors in this study and similar studies as well.

\section{Summary and Conclusions}

This paper attempts to investigate the effects of electricity price increase on its demand based on the Computable General Equilibrium (CGE) model by using the 2001 social accounting matrix. Therefore, after designing the general equilibrium model and calibrating it in the GAMS software, four scenarios include $5 \%, 10 \%, 15 \%$ and $20 \%$ increase in electricity price for different consumer sectors (household, industry and mining, agriculture and services) was introduced. The results suggest that: First, the price elasticity of electricity demand in all sectors and all scenarios is negative. Second, absolute value in all sectors and all scenarios (except the residential sector in the first scenario) is less than unity that Indicates low elasticity of electricity demand. Third, elasticity in the household sector is greater than other sectors and is close to one. A comparison of these results with similar results in different countries suggests that the elasticity in the household sector in our country is very similar to developed countries. It can be due to the low price of electricity and the use of luxury equipment in this section.

Based on the above analysis it is recommended:

- As general equilibrium models provide more reliable results than other models, it is recommended that policymakers in electricity industry to increase the electricity price consider the results of this survey.

- Since more increase in electricity price leads to reduction of elasticity (compared to the past), policymakers should not expect further savings in power consumption in the second phase of targeted subsidies in comparison with first phase. 
Citation: Abbaszadeh N, Bahmani A, Qavami M (2014) Price Elasticity of Electricity Demand in Iran Based on Computable General Equilibrium Model. J Account Mark 3: 110. doi: 10.4172/2168-9601.1000110

- National accounts Classification is based on the International Standard ISIC, while cost and power consumption statistical classification is based on Supplementary Regulations electricity tariffs (to separate residential, industrial, agricultural, commercial and public) that there is no connection between these two. Therefore, it is recommended that policymakers in power industry offer the electrical industry statistics in accordance with the international standards as possible.

- As this study used data from 2001 and we did not succeed to provide results in detailed breakdown of the electricity tariff, it is hoped that further research in the future provide these results producing required and up to date data.

\section{References}

1. Johansen L (1960) A Multi-sectoral Study of Economic Growth. Amsterdam, North-Holland.
2. Huathaker HS (1951) Some Calculation of Electricity Consumption in Great Britain. Journal of the Royal Statistical Society 114: 359-371.

3. Atakhanova Z, Howie P (2007) Electricity Demand in Kazakhstan. Energy Policy 35: 3729-3743

4. Bianco V, Manca O, Nardini S (2009) Electricity Consumption Forecasting in Italy Using Linear Regression Models. Energy 34: 1413-1421

5. Heyongxiu YX (2011) Electricity demand price elasticity in China based on computable general equilibrium model analysis. Energy 36: 1115-1123.

6. Pajouyan J, Mohammadi T (2000) Optimal pricing; Code for the electricity industry in Iran. Iranian Economic Journal 3: 39-117.

7. Khiabani N (2008) A Computable General Equilibrium model to assess the increase in price of energy carriers in economy. Energy Economics Studies 16: 1-34.

8. Eslami M (2010) Electricity price policy effects on inflation using a genera equilibrium model. Twenty-Fifth International Conference of Power, Tehran. 